\title{
Affective states associated with morphine injections
}

\author{
NELLO A. ROSSI and LARRY D. REID \\ Bradley University, Peoria, Illinois 61506
}

\begin{abstract}
Rats were placed in one compartment of an alley for $30 \mathrm{~min}$ at $1,4.5$, and $7 \mathrm{~h}$ after morphine $(10 \mathrm{mg} / \mathrm{kg})$ or saline injections on 3 consecutive days. On the 4th day, rats were allowed access to the entire alley while time spent in the compartment where they had experienced the effects following injections was tabulated. This 4-day cycle of training and testing was repeated four times. Additionally, other rats were trained and tested at $4.5 \mathrm{~h}$ after injections for the first cycle and decreased to $2 \mathrm{~h}$ for the fourth cycle, times corresponding to morphine's maximum facilitation of hypothalamic self-stimulation. On test days, rats experiencing morphine in a compartment during times corresponding to morphine's facilitation of self-stimulation, and at $1 \mathrm{~h}$ after injections, spent more time in that compartment than rats experiencing saline.
\end{abstract}

Although these experiments used rats without chronically indwelling electrodes, their purpose was to clarify results of studies in which rats' pressing for intracranial stimulation (ICS) was measured under daily doses of morphine. Tests with hypothalamic self-stimulation and morphine indicate that changes in pressing for ICS are determined by a complex interaction of dose by time after dosing by days of daily dosing. Pressing rates are depressed at $1 \mathrm{~h}$ after injections, initially, but gradually increase from the lowered levels across daily dosing (Bush, Bush, Miller, \& Reid, 1976; Olds \& Travis, 1960). Pressing rates $4 \mathrm{~h}$ after $10 \mathrm{mg} / \mathrm{kg}$ of morphine are increased, and the rates remain at the higher levels across 20 days of injections (Bush et al., 1976; Pert \& Hulsebus, 1974). The increased levels of pressing appear sooner after injections with each daily injection (Adams, Lorens, \& Mitchell, 1972; Farber \& Reid, 1976; Lorens \& Mitchell, 1973).

The fact that morphine can lead to increased pressing for ICS is of considerable theoretical interest and this paper's topic. Perhaps the increased pressing for ICS under morphine reflects potentiation of the medial forebrain bundle system's activity, and the potentiated activity is the euphoric state accompanying morphine injections (Bush et al., 1976; Farber \& Reid, 1976). Such speculation is based on a series of inferences about self-stimulation and on corollary inferences about the meaning of increased pressing for ICS. Also, there are alternative explanations of the increased rates engendered by morphine. Some germane research has been done, and these tests provide relevant data.

One explanation of morphine's facilitation of selfstimulation is that the higher rates are due to a general increase in motility, sometimes reported to follow morphine injections (Eidelberg \& Schwartz, 1970). Increased pressing, therefore, may not be a manifestation of events at the electrode tips. Lorens and Mitchell

This project was supported by Grant DA01049 of the National Institute of Drug Abuse.
(1973), however, found no correlation between general activity and increased pressing. An increase in pressing was not observed when ICS was at zero intensity after morphine injections as would be expected if rats were merely more active following injections (Overmier, Rossi, \& Reid, Note 1). Also, Koob, Spector, and Meyerhoff (1975), using rats pressing for food, water, and ICS with and without heroin injections, found that heroin facilitated pressing only for ICS. Consequently, the idea is rejected that increased motility accounts for the greater pressing.

Another explanation takes into account morphine's capability to produce analgesia (Pert \& Hulsebus, 1974). ICS that typically supports leverpressing can be shown, in certain testing procedures, to have aversive consequences, e.g., rats will press to initiate ICS but will also work to terminate ICS (Bower \& Miller, 1958; Roberts, 1958; Sakai, Reid, \& Porter, 1965; Valenstein \& Valenstein, 1964). Consequently, morphine's enhancement of self-stimulation might be due to its blocking aversive consequences which could accompany ICS. The analgesia would supposedly lead to a net greater positive affect from an ICS resulting in greater incentive and greater pressing for that heightened incentive. Farber and Reid (1976), however, reported that morphineinjected rats showed facilitated pressing for positive ICS but no facilitation for a combination of positive and aversive ICS (a measure reflecting analgesia) after a number of days of injections. Since pressing for positive ICS and for positive and aversive ICS were modified differently by morphine across days, it can be concluded that the facilitation for positive ICS and the putative analgesia are not related.

If it can be shown that morphine injections produce a positive affective state and that the positive state occurs at times when self-stimulation is facilitated, there would be independent evidence to support a conclusion that facilitation of self-stimulation is related to a positive affective state. Consequently, we sought experimental evidence germane to the issue. The premise of the 

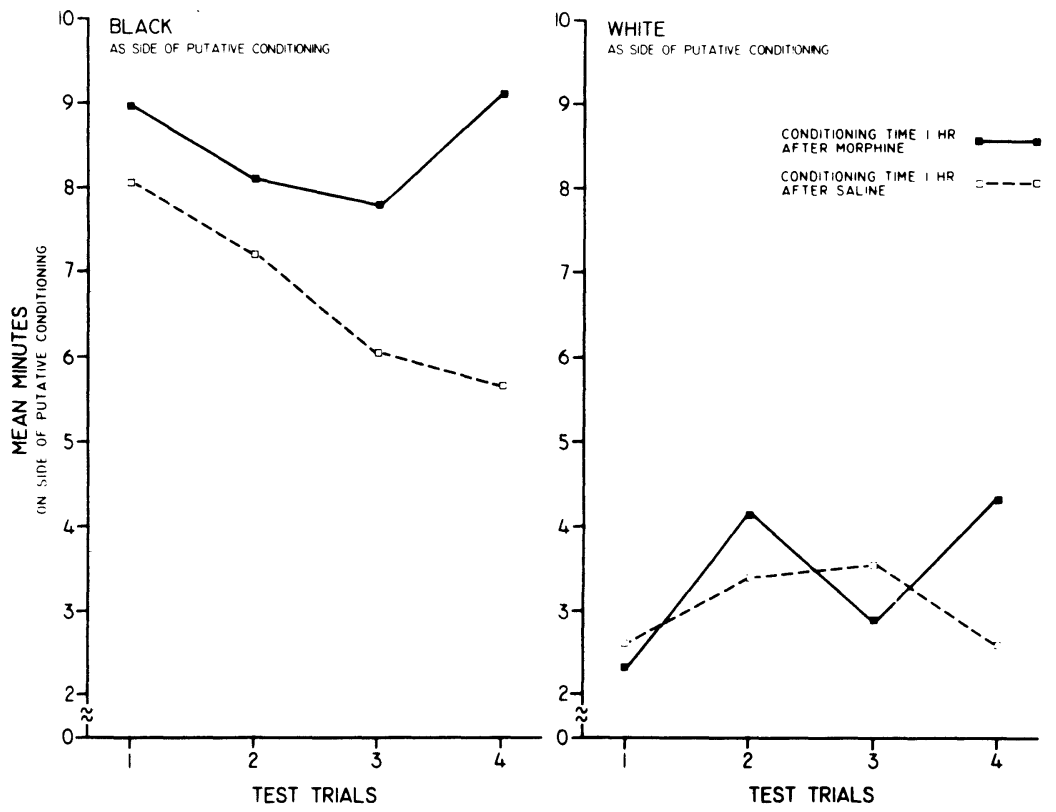

Figure 1. Mean times spent on days of test trials on the side of the apparatus in which rats experienced morphine, $10 \mathrm{mg} / \mathrm{kg}$ SQ, or saline, $1 \mathrm{~h}$ after injection.

following tests is that rats will move to places of previously experienced positive affect, will show ambivalence toward places of neutral affect, and will avoid places of experienced aversiveness. Or, conversely, if a rat, when given a choice, goes to where it had experienced morphine, it is assumed that the previous experience had positive qualities.

A pilot study was done to aid in the determination of parameters of testing. Rats were placed in a distinctive end of an alley under morphine and subsequently allowed access to the entire alley. Rats tended to favor the alley's end where they were placed $1 \mathrm{~h}$ (median time) after morphine injections but not the end associated with $4.5 \mathrm{~h}$ (median time) after morphine. Since the preliminary tests indicated the procedures were sensitive to morphine states, especially if training and testing were somewhat extended, and since the preliminary results were interesting, the following more formal tests were run.

\section{EXPERIMENT I}

\section{Method}

Subjects. The subjects were 16 adult, male, experimentally naive, Sprague-Dawley rats. The subjects were acquired from the breeder at about 43 days of age (150-175 $\mathrm{g}$ body weight) and spent 3 days in the laboratory prior to beginning the procedures. They were housed individually with food and water always available in their home cages.

Apparatus. A $98 \times 23 \times 29 \mathrm{~cm}$ alley was divided into three compartments. A middle compartment $(8 \times 23 \times 29 \mathrm{~cm})$ was separated from the other compartments by two guillotine doors. This middle compartment was gray, had a solid floor, and served as a starting point for the subjects during the testing procedure. On one side of the middle compartment was a black compartment with $1.3 \times 2.5 \mathrm{~cm}$ wire mesh floor, hereafter referred to as the black side. On the other side of the middle compartment was a white compartment with a $1.3 \times 1.3 \mathrm{~cm}$ wire mesh floor and referred to as the white side.
Procedure. The gist of the procedure was to place the subjects while under morphine, or placebo, in one of the side compartments and then subsequently give them access to the entire alley while observing the time spent in the side where they had experienced the morphine, or placebo, state. Specifically, a subject was first habituated to the apparatus once a day on 2 consecutive days by placing it in the middle compartment for $30 \mathrm{sec}$ and by then removing both doors, giving it free access to the entire alley for $30 \mathrm{~min}$. For the next 3 consecutive days, the days of training trials, a subject was placed in a side compartment (one half of the subjects in the black side and one half in the white) for $30 \mathrm{~min}$ once a day, from 45 to $75 \mathrm{~min}$ after subcutaneous (SQ) injections of either $10 \mathrm{mg} / \mathrm{kg}$ morphine sulfate or an equal volume of morphine's carrier, physiological saline. On the 4 th day, the day of a test trial, the subject was not injected and was released from the middle compartment, after a 30 -sec waiting period, and given access to the entire alley for $15 \mathrm{~min}$ at a time of day corresponding to the time of day of training trials. Time spent with at least three of the subject's paws into the side of training trials was measured.

The entire 4-day cycle ( 3 days of training trials and 1 day of test trial) was repeated four times across 16 consecutive days. Consequently, four measures were taken of the subjects' tendencies to move to or away from the side in which an injection's effects had been experienced. The design followed a 2 by 2 by 4 factorial design having repeated measures, with one factor associated with type of injection (morphine or saline), one factor associated with the compartment of putative training (black or white), and the last factor associated with the repeated measures (the four test trials).

\section{Results and Discussion}

Figure 1 is a summary of the outcomes. An analysis of variance (ANOVA) of the data from which the means of Figure 1 are derived indicate that the subjects had a marked preference for the black side of the apparatus regardless of their drug state or side of training trials, $F(1,12)=65.02, p<.01$, and this can be seen by comparing the left to the right side of Figure 1. Subjects of morphine spent more time on their side of training trials than did subjects of saline, $F(1,12)=3.76, p<.10$. The revealing finding, however, is summarized by the 
Figure 2. Mean times spent on days of test trials on the side of the apparatus in which rats experienced morphine, $10 \mathrm{mg} / \mathrm{kg}$ $\mathrm{SQ}$, or saline, $7 \mathrm{~h}$ af ter injection.
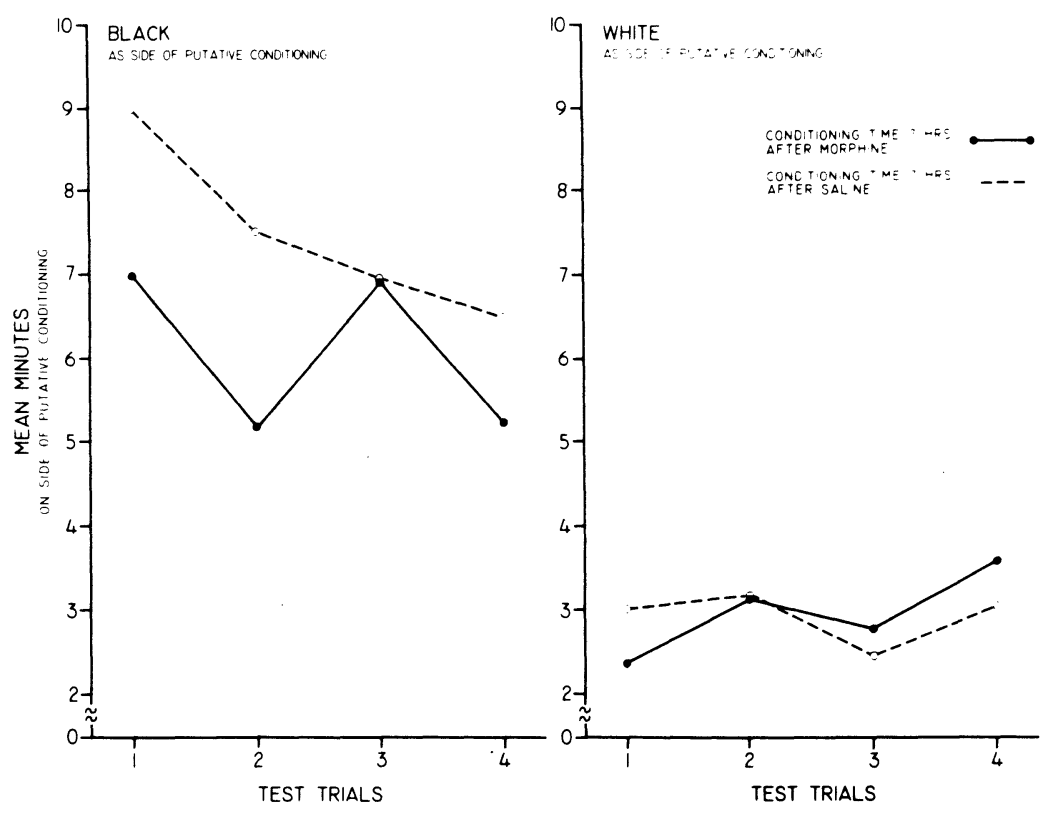

means of Figure 1 and by the Morphine-Saline by Test Trial interaction of the ANOVA, $F(3,36)=3.04$, $\mathrm{p}<.05$. Also, the Training Side by Test Trial interaction is a reliable source of variance, $F(3,36)=3.42, p<.05$. Other sources of variance do not approach statistical significance. The conclusion is reached, therefore, that the state produced $1 \mathrm{~h}$ after morphine's injection is a positive affective state, a conclusion also supported by data of the pilot study and Beach $(1957 a, b)$.

\section{EXPERIMENT II}

Adams et al. and Bush et al. concluded that pressing for ICS is facilitated subsequent to morphine injections but not facilitated $6 \mathrm{~h}$ after injections and may even be reduced $23 \mathrm{~h}$ after injections. Consequently, $7 \mathrm{~h}$ (median time) after injection was chosen as a time not anticipated to produce conditionable affect.

\section{Method}

The subjects were 16 with the same characteristics as those of Experiment I. The same apparatus and procedure was used as in Experiment I, except that the subjects were placed in the chambers 6.75 to $7.25 \mathrm{~h}$ after injections.

\section{Results and Discussion}

Figure 2 summarizes the results. As in Experiment I, the side of training is again a reliable source of variance, $F(1,12)=63.46, p<.01$. Also, the Side of Training by Test Trial interaction is statistically significant, $F(3,36)=4.22, p<.05$. All other factors do not represent reliable sources of variance, e.g., the MorphineSaline by Test Trial interaction yields an $\mathrm{F}(3,36)=1.40$, $\mathrm{p}>.25$. These data provide no support for the hypothesis that there is a conditionable affective state associated with morphine, $10 \mathrm{mg} / \mathrm{kg}, 7 \mathrm{~h}$ after injections.

\section{EXPERIMENT III}

Adams et al. found that the maximum increased pressing on the first day of injections was about $5 \mathrm{~h}$ after injections, but as days of dosing continued, the maximum increases occurred sooner and sooner after injections, e.g., after five daily injections, the maximum pressing was $3 \mathrm{~h}$ after injections. The procedures of the pilot study using $4.5 \mathrm{~h}$ after injections across days of training and testing therefore did not test the hypothesis that subjects prefer the state corresponding to times of maximum pressing for ICS, because the subjects were not placed in the chambers at the proper times. To test that hypothesis, it would be necessary, from data of Adams et al., to gradually reduce the time between injections and subjects' placement in the apparatus.

\section{Method}

The subjects were 24 adult, male, Sprague-Dawley rats ( 250 to $350 \mathrm{~g}$ ), 6 subjects a group. All were naive to morphine and the apparatus at the beginning of the procedures, and 16 subjects were naive to all experimental procedures. The other 8 subjects had served in a study of avoidance responding and were arranged factorially across the groups. The apparatus was the same as in the previous experiments. Also, the same procedures were used, except that the time period between an injection and a training or test trial was decreased with each 4-day cycle. For the first cycle, time after injections during which the subjects were in the apparatus was from 4.25 to $4.75 \mathrm{~h}$; for the second cycle, it was 2.75 to $3.25 \mathrm{~h}$; for the third cycle, it was 2.25 to $2.75 \mathrm{~h}$; and for the last cycle, it was 1.75 to $2.25 \mathrm{~h}$. From data of Adams et al., these times correspond, roughly, to times of maximum facilitation of self-stimulation by morphine injections, $10 \mathrm{mg} / \mathrm{kg}$, SQ.

\section{Results and Discussion}

Figure 3 depicts the results. As in the other experiments, the rats tended to stay in the black compartment 

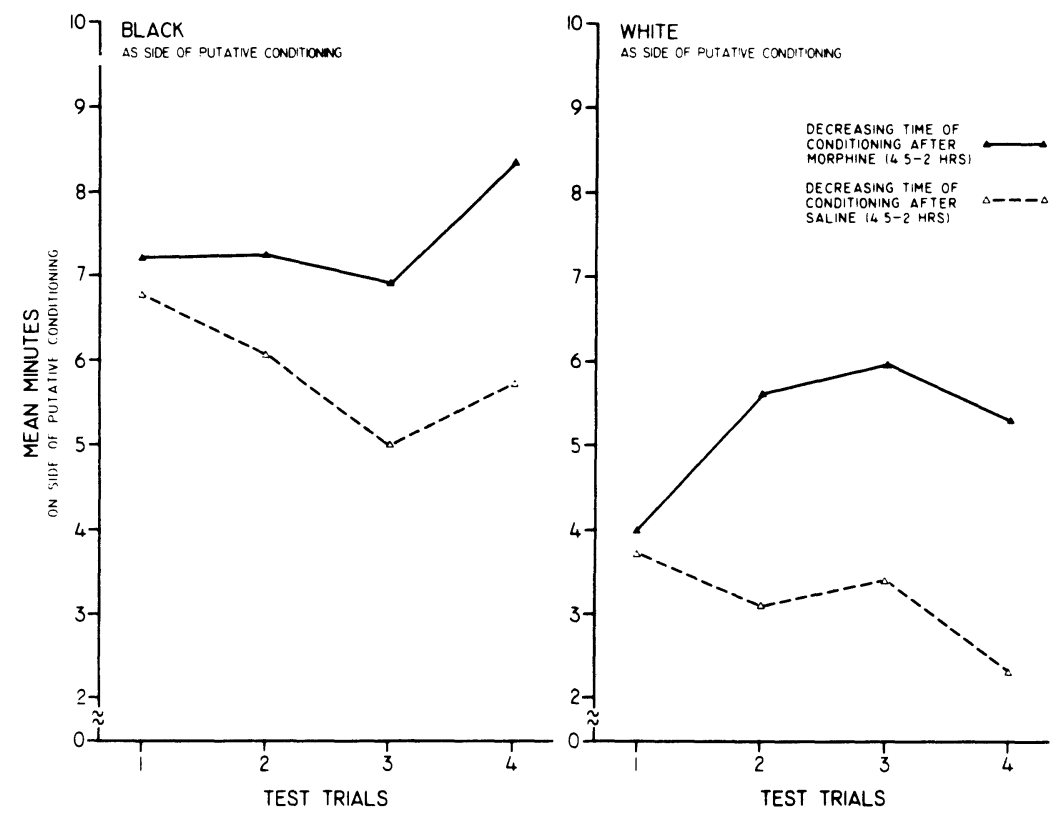

Figure 3. Mean times spent on days of test trials on the side of the apparatus in which rats experienced morphine, $10 \mathrm{mg} / \mathrm{kg}$ SQ, or saline, 4.5 to $2 \mathrm{~h}$ after injection.

regardless of conditions of training, $F(1,20)=31.83$, $p<.01$. The rats of morphine spent more time in the side of training than did the rats of saline, $F(1,20)=17.01, p<.01$. Furthermore, the MorphineSaline by Test Trial interaction is a reliable source of variance, $F(3,60)=3.64, p<.05$. Other sources of variance are not statistically significant. Student ts for correlated differences were calculated using differences between first and last test trial: $t(11)$ for morphine group $=-1.83, \mathrm{p}<.10, \mathrm{t}(11)$ for saline group $=2.75$, $p<.02$. These data support the hypothesis that injections of morphine produce a positive affective state during the periods when rats' pressing for ICS is facilitated.

\section{EXPERIMENT IV}

Data of the pilot study lead to the conclusion that the state engendered by morphine $4.5 \mathrm{~h}$ after injection does not produce a reliable preference for the place where the subjects experienced the state. The pilot study was, however, abbreviated. Consequently, we again tested rats' preference for the places experienced $4.5 \mathrm{~h}$ after $10-\mathrm{mg} / \mathrm{kg}$ morphine injections.

The saline groups of the previous three experiments, on the average, differed from one another only slightly (Figures 1, 2, and 3). To check to see if the groups of saline injections were similar to one another, an ANOVA was done comparing the performance of the three groups. The factor associated with the groups-saline yields an $F(2,22)=.97$, and the factor of the GroupsSaline by Trials yields an $F(3,66)=.28$. There was a preference, of course, for the black side, $F(1,22)=66.54, p<.01$, and there is a trials effect, $\mathrm{F}(3,66)=6.25, \mathrm{p}<.01$, and a Side by Trials interaction, $F(3,66)=3.24, p<.05$. This analysis provides no support for the notion that the various saline groups differed. Consequently, for the last experiment, only a group of morphine subjects was tested and then compared to all of the subjects of saline of the three previous experiments.

\section{Method}

Subject type, apparatus, and general procedure were the same as the previous experiments except that $(a)$ only subjects $(n=6)$ of morphine were actually run and their performance was compared to performance of all saline controls of previous experiments, and (b) the subjects were placed in their respective sides of training from 4.25 to $4.75 \mathrm{~h}$ after injections.

\section{Results and Discussion}

Results are summarized in Figure 4. An ANOVA of data from which the means of Figure 4 are derived yields the following results. The main effect of side of training, $\mathrm{F}(1,36)=70.11, \mathrm{p}<.01$, and trials, $\mathrm{F}(3,108)=4.45$, $\mathrm{p}<.01$, are reliable factors. The following interactions are reliable sources of variance: Morphine-Saline by Side of Training, $F(1,36)=7.58, p<.01$; Side of Training by Trials, $F(3,108)=3.13, p<.05$; and Morphine-Saline by Side of Training by Trials, $F(3,108)=3.12, p<.05$. Other factors are not statistically significant.

Results of the pilot study and this experiment are equivocal with respect to determining the affective state $4.5 \mathrm{~h}$ after injection. There are some indications that the state is positive (right panel of Figure 4, and the triple interaction), however, there are other indications that the state is neutral (pilot data, left panel of Figure 4, and lack of a reliable morphine-saline effect and lack of Morphine-Saline by Trials interaction). Consequently, the conclusion is that the state associated with morphine $4.5 \mathrm{~h}$ after injections is affectively neutral or, at best, weakly positive. 
Figure 4. Mean times spent on days of test trials on the side of the apparatus in which rats experienced morphine, $10 \mathrm{mg} / \mathrm{kg}$ SQ, $4.5 \mathrm{~h}$ after injection, and mean time of all saline animals from Experiments I, II, and III spent on days of test trials on the side of the apparatus in which rats experienced saline. The vertical lines indicate one standard error of the mean of the combined saline data.
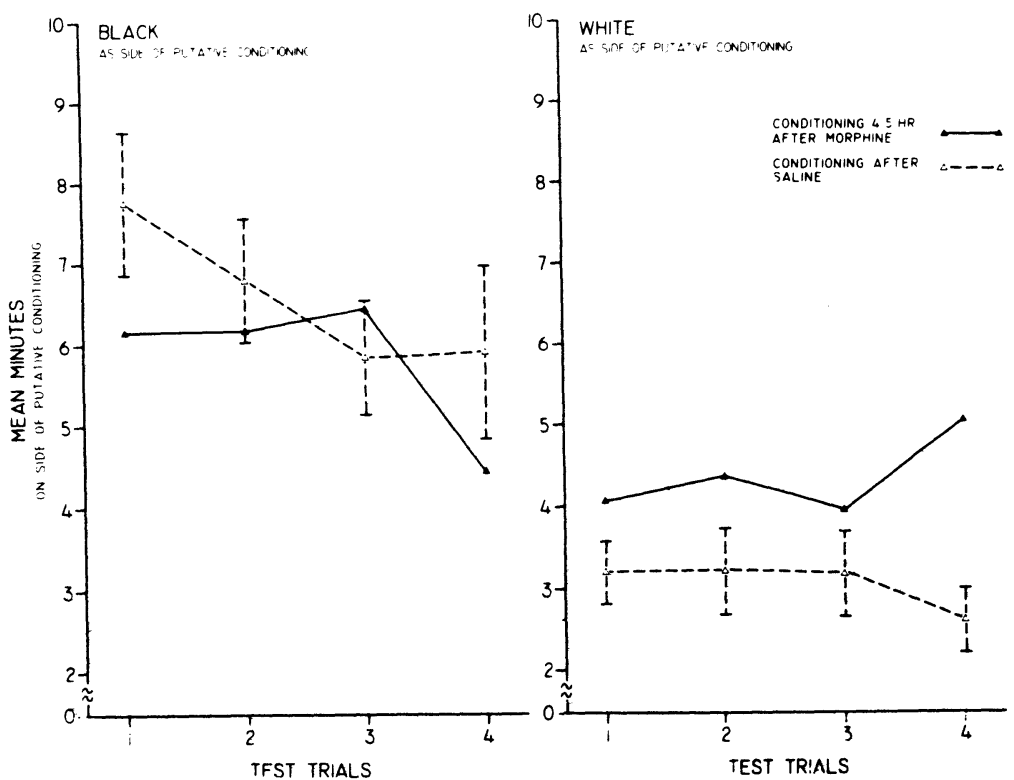

\section{GENERAL DISCUSSION}

Although the separate experiments were run at different times, the first three experiments do conform to a single complex factorial design. Since the various saline control groups performed similarly, it seems possible to draw some meaningful comparisons across the various experiments.

The states following injections by $1 \mathrm{~h}$ and the states following injections by $4.5 \mathrm{~h}$ on the first days and $2 \mathrm{~h}$ on the last days are positive, i.e., the subjects spent more time in the side where they experienced these morphine states than did the subjects of saline. Although distributions of scores of the two groups overlap considerably, thereby making conclusion based on group means tenuous, the 4.5- to 2-h group did spend, on the average, more time on the side where they experienced morphine than did the 1-h group. The states following injections by $7 \mathrm{~h}$ are neutral, i.e., the subjects spent nearly equal time in the side where they experienced these morphine states as did the subjects of saline. If means are taken as an index, it can be concluded that the state of $4.5 \mathrm{~h}$ after morphine injections is slightly positive and more positive than the state following injections by $7 \mathrm{~h}$.

Rates of self-stimulation, following the dose of morphine used here, are depressed at $1 \mathrm{~h}$ (Bush et al., 1976), but increased at times corresponding to the 4.5- to 2-h procedure (Adams et al., 1972). Self-stimulation is not facilitated at $7 \mathrm{~h}$ after the first day of injections, and there is some indication that facilitated pressing at $4.5 \mathrm{~h}$ wanes across days of injections (Adams et al., 1972); however, Bush et al. did report facilitation of pressing at $4 \mathrm{~h}$ across 20 days of injections with only a slight reduction in facilitated pressing toward the end of the 20 days, a finding corresponding to that of Pert and Hulsebus (1974).
Since the times of the $4.5-$ to 2 - $h$ procedure were chosen to correspond to periods of maximum facilitation of self-stimulation and the time of the 7-h procedure was chosen to correspond to a time of no effect on self-stimulation, and since the subjects' behavior indicates positive affect with the 4.5- to 2-h procedure and neutral affect with the 7 -h procedure, it can be concluded that there is a positive state that accompanies the times when self-stimulation is facilitated. The time of $1 \mathrm{~h}$ after injections is positive, as indexed by the alley testing, but is a time when self-stimulation rates are depressed. The subjects at $1 \mathrm{~h}$ after injections, however, are stuperous and probably incapable of fast leverpressing. As tolerance builds to the drug with respect to the incapacitating features, it is notable that the facilitation of self-stimulation appears sooner and sooner after injections. Regardless of how the initial depression of self-stimulation is explained, it is clear that during periods of facilitation of self-stimulation the subjects are experiencing a positive affective state.

There are theorists who suggest that all reinforcement for maintaining behavior of opioid assimilation is negative (Beecher, 1966; Criswell \& Levitt, 1975; Lindesmith, 1938). There is emerging, however, a collection of observations suggesting that direct, positively reinforcing events contribute to the maintenance of behavior of opioid assimilation. Recently collected verbal reports of opioid addicts lead to the conclusion that they experience euphoric effects more frequently than previously believed (McAuliffe \& Gordon, 1974). Laboratory animals will press levers to self-inject opioids and other addictive agents (Schuster, 1973; Weeks, 1962). Rats will go to places where they experience initial injections of morphine prior to time when withdrawal aversiveness could be expected (this paper). Morphine facilitates hypothalamic self-stimulation and 
supposedly directly potentiates medial forebrain bundle systems (references cited in introduction). Furthermore, morphine is known to increase adrenergic neurotransmitters associated with medial forebrain bundle (Davis, Smith, \& Khalsa, 1975; Gunne, 1963; Maynert \& Klingman, 1962) and with processes of positive intracranial reinforcement (Stein \& Wise, 1969). All of these observations are congruent with one another and suggest that morphine is a euphoriant, under certain conditions, and that it achieves its euphoric properties by facilitating activity of the medial forebrain bundle, possibly by modifying levels of adrenergic transmitters.

\section{REFERENCE NOTE}

1. Overmier, M. H., Rossi, N. A., \& Reid, L. D. Addictive agents and intracranial stimulation (ICS): Morphine and selfstimulation for low intensities of ICS. In preparation.

\section{REFERENCES}

Adams, W. J., Lorens, S. A., \& Mitchell, C. L. Morphine enhances lateral hypothalamic self-stimulation in the rat. Proceedings of the Society of Experimental Biology and Medicine, 1972, 140, 770-771.

BEACH. H. D. Morphine addiction in rats. Canadian Journal of Psychology. 1957, 11, 104-112. (a)

BEACH. H. D. Some effects of morphine on habit function. Canadian Journal of Psychology. 1957. 11. 193-198. (b)

BEecher. H. K. The use of chemical agents on the control of pain. In R. S. Knighton and P. R. Dunke (Eds.), Pain. Boston: Little. Brown. 1966.

Bower, G. H.. \& Miller. N. E. Rewarding and punishing effects from stimulating the same place in the rat's brain. Journal of Comparative and Physiological Psychology, 1958, 51, 669-674.

Bush, H. D.. Bush, M. F., Miller, M. A., \& Reid, L. D. Addictive agents and intracranial stimulation: Daily morphine and lateral hypothalamic self-stimulation. Physiological Psychology, 1976, 4, 79-85.

Criswell. H. E., \& LevitT, R. A. The narcotic analgesics. In R. A. Levitt (Ed.), Psychopharmacology. New York: Wiler. 14-5.

Davis. W. M.. Smith, S. G., \& Khalsa. J. H. Noradrenergic role in the self-administration of morphine or amphetamine. Pharmacology Biochemistry and Behavior. 1975. 3. 477-484.

Eidelberg. E.. \& Schwartz. A. S. Possible mechanism of action of morphine on brain. Nature, 1970, 225. 1152-1153.

Farber. P. D. \& \& Reid. L. D. Addictive agents and intracranial stimulation (ICS): Daily morphine and pressing for combinations of positive and negative ICS. Physiological Psychology, 1976, 4. 262-268.

GunNe. L. M. Catecholamines and 5-hydroxytryptamine in morphine tolerance and withdrawal. Acta Physiologica Scandinavica, 1963, 58, Suppl. 204, 1-91.

Koob, G. F.. Spector, N. H.. \& Meyerhoff, J. L. Effects of heroin on lever pressing for intracranial selt-stimulation, food and water in the rat. Psichophurmacologia. 1975. 42. $231-234$.

Lindesmith, A. R. A sociological theory of drug addiction. The American Journal of Sociology. 1938, 43, 593-613.

Lorens, S. A., \& Mitchell. C. L. Influence of morphine on lateral hypothalamus self-stimulation in the rat. Psychopharmacologia, 1973, 32, 271-277.

Maynert. E. W.. \& Klingman, G. I. Tolerance to morphine effects on catecholamines in the brain and adrenal glands. Journal of Pharmacology and Experimental Theraputics. 1962. 135, 285-295.

McAuliffe. W. E., \& Gordon, R. A. A test of Lindesmith's theory of addiction: The frequency of euphoria among longterm addicts. The American Journal of Sociology, 1974 , 79. $795-840$.

Olds, J., \& Travis, R. P. Effects of chloropromazine, meprobamate, pentobarbital, and morphine on selfstimulation. Journal of Pharmacology and Experimental Therapeutics, 1960, 128, 397-404.

Pert, A., \& Hulsebus, R. C. Opiate induced facilitation of self-stimulation behavior in the rat. Program and Abstract of the Society for Neuroscience, 1974, p. 372. (Abstract)

RoBerts, W. W. Both rewarding and punishing effects from stimulation of the posterior hypothalamus of cat with same electrode at same intensity. Journal of Comparative and Physiological Psychology, 1958, 51, 400-407.

Sakai. M.. Reid, L. D., \& Porter. P. B. Why is reinforcing brain stimulation turned off? In Proceedings of the 73rd Annual Convention of the American Psychological Association. 1965. Pp. 155-156.

Schuster. C. R. Self-administration of drugs. In L. Goldberg \& F. Hoffreister (Eds.). Psychic Dependence. New York: Springer-Verlag, 1973.

Stein. L.. \& WiSE. C. D. Release of norepinephrine from hypothalamus and amygdala by rewarding medial forebrain bundle stimulation and amphetamine. Journal of Comparative and Physiological Psychology, 1969, 67, 189-198.

Valenstein. E. S., \& Valenstein, T. Interaction of positive and negative reinforcing neural systems. Science, 1964, 145. $1456-1458$.

WEEKS, J. R. Experimental morphine addiction: Method for automatic intravenous injections in unrestrained rats. Science. 1962. 138. 143-144.

(Received for publication December 12. 1975; revision accepted March 3, 1976.) 